\title{
Involuntary Entrepreneurship - Evidence from Thai Urban Data
}

\author{
Alexander Karaivanov and Tenzin Yindok \\ Department of Economics \\ Simon Fraser University \\ February, 2016 \\ ** PRELIMINARY AND INCOMPLETE**
}

\begin{abstract}
We build and structurally estimate a model of occupational choice between entrepreneurial and non-entrepreneurial job alternatives. Unlike much of the previous literature, we explicitly model and distinguish between so-called "involuntary" entrepreneurship, that is, running an own business out of necessity vs. running a business because doing so is one's income-maximizing occupation. Involuntary entrepreneurship arises for those who prefer the non-business occupation (e.g., wage work) but cannot obtain it (with some probability that we estimate), due to lack of education, qualifications, unemployment, or other labor market frictions. We also allow for credit constraints and analyze their interaction with the labor market constraint. We estimate the model via GMM using the 2005 Townsend Thai urban survey. We find that $11 \%$ of all households in our sample, or approximately $16 \%$ of all households running a business are classified as involuntary entrepreneurs. We use the structural estimates to evaluate the effect of relaxing the credit and labor constraints, as well as the impact of a microfinance policy on the rate of entrepreneurship (voluntary and involuntary) and household income, on average and stratified by wealth and schooling. Our results suggest that there are large potential income gains, especially for poorer households, from relaxing either the labor market or credit constraints or from providing access to microcredit, however the fraction of involuntary entrepreneurs can only be significantly reduced by addressing the labor market constraint.
\end{abstract}




\section{Introduction}

Ever since the classic writings by Smith, Knight and Schumpeter, entrepreneurship, or running one's own business, has been viewed by most economists as an important engine of economic growth and innovation. Taxes and other government policies are often explicitly designed to help 'small businesses' grow and prosper. On the other hand, self-employment is particularly widespread in developing countries - for example, the World Bank Development Indicators data shows that more than $80 \%$ of total employment is in the form of self-employment in the poorest countries. How to reconcile the notion of entrepreneurship as a driver of growth and innovation with the fact that it is predominant in very poor countries, often with low or negative GDP growth?

As Banerjee and Duflo (2007) put it, "...it is important not to romanticize the idea of these penniless entrepreneurs". They add "...Are there really a billion barefoot entrepreneurs, as the leaders of microfinance institutions and the socially minded business gurus seem to believe? Or is it just an optical illusion, stemming from a confusion about what we call an entrepreneur?" (Banerjee and Duflo, 2011).

Obviously, the way to solve the apparent contradiction about the role of entrepreneurship in the economy is to acknowledge that entrepreneurs are not all alike. Some people start own businesses purely on their own volition, sometimes quitting a wage job to do so. Others, however, become self-employed involuntarily or by necessity, as their only option to survive. Clearly the potential policy implications differ for these two categories - while some may need tax rebates, others may need social insurance or marketable skills. While this point is easy to make, it is much harder to distinguish in the data which entrepreneurs fall in which category. Most of the existing empirical literature (reviewed in detail below) adopts a reduced form approach and uses an ad-hoc criterion to distinguish between the two categories of entrepreneurs. ${ }^{1}$ Naturally, self-identified data on involuntary entrepreneurs is rare, with one exception being the Global Entrepreneurship Monitor (GEM) survey which finds that, on average, $21 \%$ of the respondents in OECD countries and about $46 \%$ in non-OECD countries choose the second option in the question: "Are you involved in this start-up/firm to take advantage of a business opportunity or because you have no better choices for work?" (Poschke, 2012)

Along with the empirical literature, there is a large literature on occupational choice between wage work and starting a business (Banerjee and Newman, 1993; Piketty, 1997; Aghion and Bolton, 1997; Evans and Jovanovic, 1989; Lloyd-Ellis and Bernhard, 2000; Paulson et al., 2006; Karaivanov, 2012; Buera, 2009; Nguimkeu, 2014 among others). In all these papers the key assumption is that economic agents freely choose, out of all available options, the occupation they prefer the most. Typically this is taken to mean maximizing expected income. Many of the models allow for credit or labor market imperfections which shape the optimal choice by affecting the expected payoffs of the different occupations but all occupations are always considered and can be chosen by all individuals, for example, depending on an unobserved "entrepreneurial talent" variable. This

\footnotetext{
${ }^{1}$ For example, one could compare individuals who left a paid job to start a business vs. all others (Block and Wagner, 2010) or those who run an own-account business vs. those who employ other people (de Mel et al., 2012).
} 
modeling assumption is hard to reconcile with the data presented earlier, which seems to imply that some individuals would ideally choose a different occupation (e.g., wage work instead of running a business) if it were available to them.

We build and estimate using Thai urban data a structural occupational choice model that explicitly allows for the possibility that some individuals may have a restricted choice set of occupations. In particular, in our model some agents engage in self-employment due to lack of access to wage work. ${ }^{2}$ This can be motivated either by education, qualifications, and other similar barriers to finding paid work; or as an outcome of queuing for a restricted pool of wage jobs in an efficiency wage setting.

Specifically, we extend the classic occupational choice model of Evans and Jovanovic (1989). In that model, individuals who differ in their initial wealth and 'entrepreneurial ability' choose between starting a business and wage work. They can invest up to a fixed fraction of their initial wealth, $\lambda z$ in the business, representing a credit market constraint. Entrepreneurship is chosen over wage-work if the net income from running a business is larger than the income from wage work. We extend this basic framework by adding a probability with which an agent, based on his observable characteristics, does not have access to wage work. This gives rise to involuntary entrepreneurship if, in the absence of this choice constraint, the agent would have maximized his income as a wage worker. We parameterize the occupational choice (labor market) constraint in such a way that different values of the parameter correspond to different levels of the tightness of the constraint. Upon estimation, this allows the data to reveal whether the choice constraint is negligible or significant, and therefore whether our extension to the basic income-maximization model does or does not help explain the observed occupational choices in the data. Additionally, our approach allows to quantify the number of involuntary entrepreneurs and their distribution based on observables such as initial wealth and years of schooling.

We use the Townsend Thai Project Initial Household Survey (Urban Area) of 2005 (NORC, 2008). It covers six different Thai provinces (Chachoengsao, Lopburi,Srisaket, Buriram, Phrae, and Satun), and surveys households in the municipal areas considered urban and semi-urban. The data include retrospective information on wealth and assets, income, household business, lending and borrowing, and individual level demographic and occupation variables. In our sample $66.1 \%$ of all households are classified as entrepreneurs or 'in business', based on answering "yes" to the question whether any household member has an own business. The rest of the households are classified as "non-business", e.g., working for a wage.

We estimate the structural parameters of the model via the generalized method of moments (GMM) by matching observed and model-predicted occupations and income levels conditional on households' initial wealth and education. Entrepreneurial ability is modeled as a source of unobserved heterogeneity. We match 10 moments (6 occupational choice and six income-based) and estimate 9 structural parameters.

The baseline estimates indicate that $10.7 \%$ of all households in our sample, or $16.1 \%$ of all

\footnotetext{
${ }^{2}$ Unemployment is ruled out as a viable choice, e.g., due to lack of social safety nets while the other typical option from the literature, subsistence agriculture, is not applicable to the urban environments we have in mind.
} 
households who report running a business, are classified by the model as involuntaryentrepreneurs. The predicted probability (propensity) of involuntary entrepreneurship at the GMM estimates varies across the agents between as high as .42 to 0 and it is decreasing in the years of schooling and in initial wealth. That is, poorer and less educated agents are more likely to be involuntary entrepreneurs (49\% of them are among households with both initial wealth and schooling below the median).

At the GMM parameter estimates we find that the credit constraint is more likely to bind for voluntary entrepreneurs (it binds for $58 \%$ of them) than for involuntary entrepreneurs (26\%). The reason is that voluntary entrepreneurs have higher entrepreneurial ability on average and hence are more likely to be credit constrained for a given wealth level. Voluntary entrepreneurs are estimated to earn significantly higher income on average (583 thousand Baht) compared to involuntary entrepreneurs (85 thousand Baht) or households not running a business (191 thousand Baht).

We also look at three counterfactuals using simulated data from the model at the GMM estimates. First, we consider the elimination of the labor market constraint - that is, each agent is able to choose their income-maximizing occupation, as in the existing literature (Evans and Jovanovic, 1989). Naturally, this reduces the rate of entrepreneurship in the economy since only the voluntary entrepreneurs remain. Mean net income in the economy goes up by $1.7 \%$ but the gains are unevenly spread over the income distribution with the 10 th income percentile receiving a $6.8 \%$ increase compared to the baseline with binding labor market constraint versus only $0.8 \%$ increase at the 90th percentile. While all households weakly gain from the counterfactual, eliminating the constraint has a composition effect which lowers the average income of ex-post non-business households because of the entry of the relatively less-skilled former involuntary entrepreneurs and raises the mean income of entrepreneurs.

The next counterfactual we consider is relaxing the credit constraint, which we perform by doubling the credit tightness parameter $\lambda$ controlling the maximum size of capital that can be borrowed and invested. As with the labor constraint, this policy is Pareto improving by construction. At our GMM estimates, we find that relaxing the credit constraint in this way has only a minor effect on the rate of involuntary entrepreneurship among those running a business (it falls from $16.1 \%$ to $15.8 \%$ ). This suggests that the labor market constraint is relatively more important. However, relaxing the credit constraint has significant impact on income in the economy via enabling entrepreneurs to invest more. Mean income goes up by $3.4 \%$ accompanied with gains across the income distribution. The income gains are largest again among poorer households $(6.9 \%$ at the 10th income percentile).

The third counterfactual we consider introduces the option for model agents to take a microfinance loan of up to $10 \%$ of the median gross income in the data, $M$ (20 thousand Baht). The loan has the same interest rate as in the baseline economy, so all it does is effectively raises the credit upper bound from $\lambda z$ to $\lambda z+M$. Again, we find that, at our GMM estimates, the microfinance policy does not change the rate of involuntary entrepreneurship by much (it falls from $16.1 \%$ to $15.5 \%$ of all entrepreneurs) but it does raise the overall rate of entrepreneurship in the model economy from $65.9 \%$ in the baseline to $66.8 \%$. The effect of the microfinance policy is more significant 
on households income. Average income goes up by $3 \%$ but households at the bottom of the income distribution benefit more from the ability to expand their businesses (or select into a higher-income occupation) - the income gain is $12.2 \%$ at the 10 th income percentile. We also analyze the incidence of the policy by household initial wealth and schooling and find that the largest gains (up to $40 \%$ income increase occur for households with both very low wealth and schooling).

\section{Review of the literature}

Much of the existing empirical work on the topic looks at 'voluntary' vs. 'involuntary' entrepreneurs by using an ad-hoc definition based on available data. For example, Block and Wagner (2010) finds a $16 \%$ earnings premium in Germany for individuals who start a business after voluntarily leaving their previous job, compared to those who start a business after losing their previous job. Using data from six ex-USSR countries, Earle and Sakova (2000) find that own-account workers would earn more as employees, and conclude that at least some of them are occupational choice constrained. In Sri Lanka, de Mel et al (2010) find that, along a wide range of dimensions (parental and childhood background, labor history, measures of ability and risk-attitude), the majority of own-account workers resemble more wage-workers than larger firm owners.

A few papers analyze entrepreneurship in the framework of income maximization while allowing for a wage-market friction, as we do here. For example, Falco and Haywood (2013) estimate the returns to observable characteristics in self-employment vs. wage work in Ghana. They assume that 'job queueing' may exist in the wage market which is modeled as an entry cost possibly depending on unobservable worker characteristics. The focus of the paper is on obtaining consistent estimates of the returns to observables and unobservables in each sector, and therefore its results are not directly comparable to ours.

Another related paper is Gunther and Launov (2012) who model observed income as a finite mixture of incomes from a segmented labor market. Accounting for selection, they model earnings in each segment as a linear function of demographic variables (sex, age, education and training, religion, etc). ${ }^{3}$ Using a 1998 Ivorian household survey, they conclude that the informal sector is made up of at least two latent segments. The model allows to determine the segment in which a person's income would be maximized. They show that $44 \%$ of informal sector workers are predicted to maximize their earnings in a different labor market segment than the one they are engaged in, which is interpreted to imply that involuntary employment is a significant phenomenon in the urban labor market. Our approach differs in that, instead of a statistical model, we propose a structural economic model of involuntary entrepreneurship based on maximizing behavior subject to constraints. We are also able to distinguish between labor market-constrained and credit-constrained households.

Our paper also differs from two recent working papers on entrepreneurship in a structural setting, respectively by Banerjee et al. (2015) and Donovan (2015). Banerjee et al. use data from a microfinance randomized trial in India and define two types of entrepreneurs: "gung-ho entrepreneurs" (GE) defined as those who already owned a business before the intervention, and "reluctant entrepreneurs" (RE), defined as those without a business prior to the intervention. Their

\footnotetext{
${ }^{3}$ In their sample, $52.6 \%$ of those between the age of 15 and 65 years are inactive. In contrast, we use household level business ownership and all our households are occupied in at least one income-earning activity.
} 
definition thus differs from our endogenous determination of voluntary vs. involuntary entrepreneurship, within the structural model. The authors estimate a model of technology choice in which REs only have access to a decreasing returns to scale technology, while GEs can, in addition, access another technology with large fixed costs but higher return. Using data on various outcome variables separately for the GEs and REs in the treatment and control neighborhoods, they find that most of the impact from the treatment is driven by the GEs who expand their businesses as opposed to REs for whom most effects are insignificant. Unlike in our paper the author's focus is not on determining who and how many the 'involuntary' entrepreneurs are (a particular ex-ante definition is used instead) but on quantifying the heterogeneity in policy outcomes.

Donovan (2015) defines "subsistence entrepreneurs" similarly to us here, as business owners who would accept a salaried job if offered. He focuses on the role of unemployment and search frictions. In his model, subsistence entrepreneurship arises as a result of low unemployment benefits and financial market imperfections. He studies the impact of the resulting misallocation between entrepreneurs and salaried workers on the firm size distribution and the impact of lending to poor entrepreneurs. The model is tested empirically with data from Chile and Mexico, finding that misallocated business owners earn lower profit conditional on observables and are more likely to have left their previous job involuntarily.

\section{Model}

\subsection{Preferences, endowments, and technology}

Consider a large number of households (agents) who are risk-neutral and have strictly increasing preferences over expected income. The agents differ in their initial endowments of a single investment good, $z$ where $z \geq 0$. They also differ in two productive characteristics: $x \in[0, \bar{x}]$ which can be

thought of as 'schooling' or, more generally, 'labor market skills', and $\theta \in\left[\theta_{\min }, \bar{\theta}\right]$ which will be interpreted as entrepreneurial 'talent' or ability.

There are two occupations/technologies. The first is a "business" or "entrepreneurship" technology, $E$ which requires capital investment $k>0$ and one agent to operate and yields expected output

$$
q^{E}(\theta, z)=\theta k^{\alpha}
$$

where $\alpha \in(0,1)$. There is no minimum scale or fixed costs to start up a business, so anyone with $z>0$, no matter how small can be an entrepreneur.

The second occupation or technology does not require capital and yields expected output

$$
q^{A}(x, z)=\mu(1+x)^{\gamma}
$$

Above, the parameter $\mu>0$ corresponds to what a person with labor market skills $x=0$ would earn while $\gamma \geq 0$ governs the sensitivity of $q^{A}$ to increases in $x$. We will interpret occupation $A$ as the "alternative" or "non-business" occupation. It can include wage work or other similar activities, 
the income from which increases in $x$.

\section{$2.2 \quad$ Financial Market}

As in Evans and Jovanovic (1989), hereafter, EJ assume that the agents have access to a financial intermediary via which they can save or borrow at gross interest rate $r \geq 1$. The credit market is imperfect. Due to a limited enforcement problem, the maximum amount $k$ that an agent can invest is $\lambda z$ where $\lambda>0$ is a parameter capturing the severity of credit constraint. ${ }^{4}$ Setting $\lambda$ very large corresponds to perfect credit markets. Setting $\lambda=0$ corresponds to a missing credit market (only saving is possible). If an agent has a sufficiently large wealth, she would be able to invest the optimal amount of capital in her firm and the credit constraint will not bind. In contrast, if an agent has relatively low wealth they will be credit-constrained and invest $\lambda z$ even though the marginal product of capital exceeds the cost of funds $r$ at that investment level.

Agents who are employed in the $A$ occupation do not need capital $k$, so they save their initial endowment which results in expected income of:

$$
y^{A}(x, z)=\mu(1+x)^{\gamma}+r z
$$

Agents who are employed in the $E$ occupation (entrepreneurs) would either save or borrow depending on their desired investment $k$. That is, their expected income can be written as

$$
y^{E}(\theta, z)=\theta k^{\alpha}+r(z-k)
$$

The optimal investment level $k$ will be determined below.

\subsection{Involuntary Entrepreneurship}

In EJ (1989), given the agents' preferences, they would prefer the occupation which yields higher expected income. That is, absent any constraints on their choice set an agent would choose the occupation which achieves the maximum of $y^{E}(\theta, z)$ and $y^{A}(x, z)$. Here, we depart from EJ by assuming that, depending on the agent's characteristic $x$ (education, labor market skills), the agent's access to occupation $A$ is restricted with some probability. For instance, agents with lower level of $x$ find it harder to find wage work; government or private sector jobs require diplomas, qualifications, certificates, etc.

Specifically, let $P_{x}$ be the probability with which an agent with labor market skills $x$ does not have access to occupation $A$ in the current period. That is, with probability $P_{x}$ such agent only has access to occupation $E$, while with probability $1-P_{x}$ she can choose either $E$ or $A$. If occupation $E$ is what this agent would have chosen to maximize her expected income, then this occupational choice (labor market) constraint is not binding. However, if $y^{A}>y^{E}$ for this agent, then she will be an "involuntary" entrepreneur - someone who engages in the $E$ occupation purely out of necessity.

\footnotetext{
${ }^{4}$ The $\lambda z$ upper bound can be easily micro-founded by a limited enforcement friction, see PTK (2006) for a discussion.
} 
In our baseline setting we assume that

$$
1-P_{x}=\left(\frac{1+x}{1+\bar{x}}\right)^{\eta}
$$

where $\bar{x}$ is the largest possible value of $x$ and $\eta \geq 0$ is a parameter that governs the tightness of the choice constraint for different values of $x$. For example, the case $\eta=0$ corresponds to $P_{x}=0$, that is, all agents are able to choose freely between both occupations, as in the EJ model. In contrast, the case $\eta<1$ corresponds to the occupational choice constraint becoming less tight quickly for $x$ relatively low, while $\eta>1$ corresponds to the case when the constraint is relaxed only for relatively large values of $x$.

The economic interpretation of (1) is that agents with higher education or other labor market skills, $x$ are more likely to have access to both occupations in a given moment of time. This is also consistent with the "queuing for jobs" interpretation of [Ref] mentioned in the introduction.

\subsection{Optimal Investment and Occupational Choice}

Remember that income from entrepreneurship equals

$$
y^{E}(\theta, z)=\theta k^{\alpha}-r(z-k) .
$$

Thus, if the credit constraint is not binding, an agent with initial wealth $z$ and ability $\theta$ would optimally want to invest the first-best (unconstrained) capital amount, $k_{u}(\theta)$ solving

$$
k_{u}(\theta) \equiv \arg \max _{k}\left\{\theta k^{\alpha}-r k\right\}=\left(\frac{\theta \alpha}{r}\right)^{\frac{1}{1-\alpha}}
$$

Note that $k_{u}(\theta)$ is increasing in $\theta$, implying that more talented entrepreneurs would want to invest more. The first-best capital amount does not depend on the entrepreneur's initial wealth $z$. Intuitively, in a world without credit constraints, all productive projects will be financed at the levels of $k$ that equalize marginal product to marginal cost.

With credit constraints, however, the first-best level of capital is only feasible if $k_{u}(\theta)=$

$\left(\frac{\theta \alpha}{r}\right)^{\frac{1}{1-\alpha}} \leq \lambda z$. Define $B(z)$ as the threshold level of entrepreneurial talent $\theta$ at which $k_{u}(\theta)=\lambda z$, that is,

$$
B(z) \equiv \frac{r}{\alpha}(\lambda z)^{1-\alpha}
$$

In other words, for a given initial wealth $z$, the value $B(z)$ is the maximum level of talent $\theta$ at which an agent is financially unconstrained and able to invest $k_{u}(\theta)$. For given wealth $z$, note that the credit constraint is therefore more likely to bind for more talented entrepreneurs. If $\theta>B(z)$ the agent would optimally invest the maximum possible amount, $\lambda z$ which is less than $k_{u}(\theta)$ since the marginal product of capital exceeds the marginal cost. 
We therefore obtain,

$$
\begin{gathered}
y^{E}(\theta, z)=\left\{\begin{array}{cc}
\theta\left[k_{u}(\theta)\right]^{\alpha}+r\left(z-k_{u}(\theta)\right) & \text { if } \quad \theta \leq B(z) \\
\theta(\lambda z)^{\alpha}+r(z-\lambda z) & \text { if } \quad \theta>B(z)
\end{array}\right. \\
\text { or, } y^{E}(\theta, z)-r z=\left\{\begin{array}{ccc}
(1-\alpha) \theta^{\frac{1}{1-\alpha}}\left(\frac{\alpha}{r}\right)^{\frac{\alpha}{1-\alpha}} & \text { if } \quad \theta \leq B(z) \\
\theta(\lambda z)^{\alpha}-\lambda r z & \text { if } \quad \theta>B(z)
\end{array}\right.
\end{gathered}
$$

Alternatively, an agent who has access to the $A$ (non-business) occupation earns,

$$
y^{A}(z, x)=\mu(1+x)^{\gamma}+r z
$$

Define

$$
\Delta(z, \theta, x) \equiv y^{E}(\theta, z)-y^{A}(z, x)
$$

as the expected income differential between entrepreneurship and the alternative occupation. We obtain the following result, which essentially re-states the main trade-off from Evans and Jovanovic (1989)'s paper on credit-constrained occupational choice.

\section{Proposition 1}

An agent with initial wealth $z$ and characteristics $(\theta, x)$ who has access to both the entrepreneurial and alternative occupations, $E$ and $A$ would optimally choose entrepreneurship, $E$ if

$$
\Delta(z, \theta, x) \geq 0 \Leftrightarrow\left\{\begin{array}{cc}
\theta \geq A(x) & \text { if } \theta \leq B(z) \\
\theta \geq C(x, z) & \text { if } \theta>B(z)
\end{array}\right.
$$

where $A(x) \equiv\left(\frac{\mu}{1-\alpha}\right)^{1-\alpha}(1+x)^{\gamma(1-\alpha)}\left(\frac{r}{\alpha}\right)^{\alpha}, B(z) \equiv \frac{r}{\alpha}(\lambda z)^{1-\alpha}$, and $C(z, x) \equiv(\lambda z)^{-\alpha}\left[\mu(1+x)^{\gamma}+r \lambda z\right]$.

Proof: see appendix.

\subsection{The probability of entrepreneurship}

We follow the literature and assume that the entrepreneurial ability $\theta$, while observable to the agents in the model, is unobservable to the econometrician. In contrast initial wealth $z$ and the labor market characteristics $x$ are known to all. Thus, for a given distribution of $\theta$ and given $z$ and $x$ the model implies a probability that an agent chooses to be an entrepreneur (occupation $E$ ) or not (occupation $A$ ). In section 4 we compute and use these predicted probabilities to estimate the structural parameters of the model based on the observed occupational status of households in the Thai urban data. In addition, the model has implications for the probability/fraction of involuntary entrepreneurs which is a status unobserved in the data.

Proposition 1 implies that, suppressing the arguments in expressions $A(x), B(z), C(z, x)$, and 
$\Delta(\theta, z, x)$ and using $P$ to denote probabilities,

$$
\begin{aligned}
P(\Delta & \geq 0)=P(\Delta \geq 0 \mid \theta>B) P(\theta>B)+P(\Delta \geq 0 \mid \theta \leq B) P(\theta \leq B) \\
& =P(\theta \geq C \mid \theta>B) P(\theta>B)+P(\theta \geq A \mid \theta \leq B) P(\theta \leq B) \\
& =P(\theta \geq C \wedge \theta>B)+P(\theta \geq A \wedge \theta \leq B)
\end{aligned}
$$

For given initial wealth $z$ and labor market skills $x$, the exact ordering of $A(x), B(z)$ and $C(z, x)$ is completely determined.

To compute the probabilities in (5) we need an assumption on the distribution of the unobserved heterogeneity variable $\theta$ (entrepreneurial talent). We follow PTK (2006) and assume,

$$
\begin{gathered}
\ln \theta=\delta_{0}+\delta_{1} \ln z+\delta_{2} \ln (1+x)+\varepsilon \\
\text { where } \varepsilon \mid z, x \sim N(0, \sigma)
\end{gathered}
$$

The interpretation is that entrepreneurial ability can be correlated with initial wealth $z$ and the observable characteristics $x$ (in the estimation $x$ is proxied by years of schooling of the principal earner) but we also allow a random talent component, $\varepsilon$. The distributional parameters $\delta_{0}, \delta_{1}, \delta_{2}$ and $\sigma$ will be estimated together with the rest of the structural parameters such as $\alpha, \gamma, \lambda, \mu$.

Let $\mathbf{1}_{B>A}$ denote the indicator function equaling one if $B>A$ for given $(x, z)$ and zero otherwise. It is easy to show that, for any given $(x, z)$, the inequality $B>A$ is mathematically equivalent to the inequality $B>C$. Denote the conditional expectation of $\ln \theta$ by

$$
\bar{\theta}(z, x)=\delta_{0}+\delta_{1} \ln z+\delta_{2} \ln (1+x)
$$

we obtain the following result.

\section{Lemma 1}

For an agent with characteristics $(z, x)$ who has access to both the entrepreneurial and alternative occupations $E$ and $A$ the probability (likelihood) of choosing entrepreneurship equals,

$$
\tilde{P}_{E} \equiv P(\Delta(\theta, z, x) \geq 0)=\mathbf{1}_{B>A}(1-\Phi(a))+\left(1-\mathbf{1}_{B>A}\right)(1-\Phi(c))
$$

where $a \equiv \frac{\ln A(x)-\bar{\theta}(z, x)}{\sigma}$ and $c \equiv \frac{\ln C(z, x)-\bar{\theta}(z, x)}{\sigma}$.

\subsection{Involuntary Entrepreneurship}

Denote by $\mathbf{1}_{E}$ the indicator function for choosing entrepreneurship in the model, conditional on $x$ and $z$. By the Law of total probability:

$$
P\left(\mathbf{1}_{E}=1\right)=P\left(\mathbf{1}_{E}=1 \mid \Delta \geq 0\right) P(\Delta \geq 0)+P\left(\mathbf{1}_{E}=1 \mid \Delta<0\right) P(\Delta<0)
$$

where $P(\Delta \geq 0)$ is given by (7) in Lemma 1 . 
Table 1: Voluntary and involuntary entrepreneurship

\begin{tabular}{c|c|c} 
& $1_{E}=0$ & $1_{E}=1$ \\
\hline$\Delta \geq 0$ & $\mathrm{~N} / \mathrm{A}$ & voluntary entrepreneur \\
& $P\left(\Delta \geq 0,1_{E}=0\right)=0$ & $P\left(\Delta \geq 0,1_{E}=1\right)=P(\Delta \geq 0)$ \\
\hline$\triangle<0$ & Non-entrepreneur & involuntary entrepreneur \\
& $P\left(\Delta<0,1_{E}=0\right)=P(\Delta<0)-P_{x} P(\Delta<0)$ & $P\left(\Delta<0,1_{E}=1\right)=P_{x} P(\Delta<0)$
\end{tabular}

According to the model, $P\left(\mathbf{1}_{E}=1 \mid \Delta \geq 0\right)=1$, since any agent who can choose between the two occupations and earns higher expected income by being entrepreneur $(\Delta \geq 0)$ would choose occupation $E$. The model also implies that $P\left(\mathbf{1}_{E}=1 \mid \Delta<0\right)=P_{x}$ where $P_{x}$ was defined in (1) in Section 2.3. Therefore,

$$
P_{E} \equiv P\left(\mathbf{1}_{E}=1\right)=P(\Delta \geq 0)+P_{x} P(\Delta<0)
$$

That is, the overall probability of entrepreneurship $P_{E}$ can be decomposed into two terms. The first term, $P(\Delta \geq 0)$ corresponds to the probability of entrepreneurship conditional on $z$ and $x$ that would arise if all agents chose occupation $E$ based solely on expected income maximization, as assumed in the previous literature, for example EJ (1989). The second term $P_{I E} \equiv P_{x} P(\Delta<0)$ is the additional probability of entrepreneurship, relative to the basic income maximization model, which we interpret as the probability/fraction of involuntary entrepreneurship. Note that $P_{I E}$ is a function of an agent's initial wealth $z$, her labor market skills $x$, and the structural and distributional parameters of our model. The following table summarizes the above discussion.

\section{Data}

We use data from the Townsend Thai Project's 2005 Urban Annual Resurvey. ${ }^{5}$ The main outcome variable of interest is household business ownership. We measure business ownership in the data in terms of whether a household reports that they own at least one business at the time of the survey. Thus, it is a binary variable equal to 1 if the household owns a business and zero otherwise. The corresponding variable in the model is $\mathbf{1}_{E}$. In the estimation we also use the annual gross income of households, defined as their income excluding transfers from remittance, government programs, and interest. The model counterparts are $q^{E}=\theta k^{\alpha}$ and $q^{A}=\mu(1+x)^{\gamma}$ for business and not business households, respectively.

Initial household wealth, $z$ is measured as the total value (in 2005 Thai baht) of landholdings, household durables and agricultural assets owned by a household five years prior to the survey. The reason for this back-dating is to avoid potential simultaneity problems between occupational status and current wealth. Recall that, in the model, initial wealth $z$ affects the investment potential of

\footnotetext{
${ }^{5}$ Full details are available at cier.uchicago.edu.
} 
a household. We are therefore assuming that the level of pre-existing, year 2000 wealth measure we construct is free of reverse causality. Also, note that in the model, we allow initial wealth to be correlated with the level of entrepreneurial talent $\theta$, and therefore, we capture the possibility that more talented households may save more in anticipation of becoming business owners.

We proxy the model variable $x$, interpreted as education or other labor market characteristics or qualifications, by the years of schooling of the principal earner in the household. We use data on individual occupations and worker type within the household to identify the principal earner. For business households, the principal earner is the member whose occupation and worker-type matches the reported business ownership type (for households running more than one business, the principal earner is defined as the business owner associated with the largest business in terms of assets). For non-business households, the principal earner is defined as the wage-earning member (for households with multiple wage-earners, the principal earner is the member earning the highest monthly wage income).

From the full survey sample, we construct a sub-sample that we use to estimate the model as follows. We exclude all households in the top one percentile of the initial wealth distribution, all households with zero initial wealth or zero gross income, and all households for which the principal earner could not be identified. ${ }^{6}$

Table 2 shows that $66 \%$ of the households in our final sample report running a business. Using data on income sources, Table 2 also shows that business and wage work are the most important sources of income for households. $49.4 \%$ of all households in our sample derive the majority of their annual (gross) income from running a business while $36.7 \%$ of all households do so from wages. A small number, $2.3 \%$ of households derive the largest part of their income from farming (rice, other crops, and livestock-raising).

Table 2 - Occupation and Source of Income

\begin{tabular}{lcc}
\hline Self-reported business ownership & Number & Percent \\
\hline yes & 786 & 66.1 \\
no & 403 & 33.9 \\
total & 1,189 & 100 \\
& & \\
\hline Major source of annual gross income & Number & Percent \\
\hline business & 588 & 49.4 \\
wage & 436 & 36.7 \\
farming & 27 & 2.3 \\
transfers & 108 & 9.1 \\
other & 30 & 2.5 \\
total & 1,189 & 100 \\
\hline
\end{tabular}

Notes: The sample excludes the top percentile of the wealth distribution, households with zero income, and where a principle earner could not be identified.

\footnotetext{
${ }^{6}$ Because of data limitations we were not able to identify a principal earner for about $15 \%$ of all surveyed households.
} 
Table 3 summarizes the key variables used in reduced form and structural estimation.

Table 3 - Summary Statistics

\begin{tabular}{|c|c|c|c|}
\hline \multirow{2}{*}{$\begin{array}{l}\text { Variable } \\
\text { wealth } 5 \text { years ago }(000 \text { s of baht })^{*}\end{array}$} & \multicolumn{2}{|c|}{ BusinessNon-business } & \multirow{2}{*}{ All } \\
\hline & 620.5 & 469.4 & \\
\hline & $(814.8)$ & $(682.3)$ & $(775.5)$ \\
\hline & {$[335.1]$} & {$[235.1]$} & {$[305.0]$} \\
\hline \multirow[t]{3}{*}{ annual gross income (000s of baht)* } & 513.6 & 164.7 & 395.3 \\
\hline & $(1313.2)$ & $(132.5)$ & $(1074.9)$ \\
\hline & {$[276.8]$} & {$[126.0]$} & {$[200.8]$} \\
\hline \multirow[t]{2}{*}{ schooling of principle earner (years)* } & 7.3 & 9.8 & 8.1 \\
\hline & $(4.0)$ & $(4.7)$ & $(4.5)$ \\
\hline \multirow[t]{2}{*}{ age of principle earner* } & 49.4 & 41.2 & 46.6 \\
\hline & $(11.0)$ & $(13.1)$ & $(12.3)$ \\
\hline \multirow[t]{2}{*}{ male (gender of principle earner)* } & 0.45 & 0.59 & 0.50 \\
\hline & $(0.50)$ & $(0.49)$ & $(0.50)$ \\
\hline \multirow[t]{2}{*}{ household size } & 4.28 & 4.35 & 4.30 \\
\hline & $(1.90)$ & $(1.83)$ & $(1.87)$ \\
\hline sample size & 786 & 403 & 1189 \\
\hline sample proportion & $66.1 \%$ & $33.9 \%$ & $100 \%$ \\
\hline
\end{tabular}

Notes: The sample excludes the top percentile of the wealth distribution, households with zero income and where a principal earner could not be identified. Mean, standard deviation (in parentheses) for all variables, median (in brackets) for monetary values. Wealth and income are reported in thousands of 2005 Thai baht. $\left({ }^{*}\right)$ difference-in-means test between business and non-business is significant at the $1 \%$ level.

\subsection{Determinants of business ownership - reduced form evidence}

Table 4 reports the coefficient estimates of probit regressions of business ownership (a binary variable equal to one if the households report owning a business) on initial wealth, schooling, and additional household characteristics. 


\begin{tabular}{|c|c|}
\hline Variable & Coefficient estimate \\
\hline wealth 5 years ago (mln Baht) & $\begin{array}{c}0.431^{* * *} \\
(0.137)\end{array}$ \\
\hline square of wealth 5 years ago & $\begin{array}{c}-0.070 * * * \\
(0.033)\end{array}$ \\
\hline schooling of principle earner & $\begin{array}{c}0.197^{* * *} \\
(0.044)\end{array}$ \\
\hline schooling squared & $\begin{array}{c}-0.015^{* * *} \\
(0.002)\end{array}$ \\
\hline age of principle earner & $\begin{array}{c}0.028^{* * *} \\
(0.004)\end{array}$ \\
\hline male (gender of principle earner) & $\begin{array}{c}-0.450 * * * \\
(0.084)\end{array}$ \\
\hline household size & $\begin{array}{l}0.040^{* *} \\
(0.023)\end{array}$ \\
\hline province $=$ Chachoengsao & $\begin{array}{l}-0.127 \\
(0.144)\end{array}$ \\
\hline province $=$ Buriram & $\begin{array}{c}-0.437^{* * *} \\
(0.142)\end{array}$ \\
\hline province $=$ Sisaket & $\begin{array}{l}-0.006 \\
(0.154)\end{array}$ \\
\hline province $=$ Phrae & $\begin{array}{c}-0.478^{* * *} \\
(0.138)\end{array}$ \\
\hline province $=$ Satun & $\begin{array}{c}-0.762^{* * *} \\
(0.145)\end{array}$ \\
\hline intercept & $\begin{array}{l}-0.992^{*} \\
(0.319)\end{array}$ \\
\hline sample size & 1189 \\
\hline
\end{tabular}

Notes: Dependent variable is an indicator for whether household reports owning a business in 2005. Base category for province is Lopburi. ${ }^{*} \mathrm{p}<0.10,{ }^{* *} \mathrm{p}<0.05,{ }^{* * *} \mathrm{p}<0.01$.

\section{Structural Estimation}

We have a sample of $N$ households, $i=1, \ldots, N$ for whom we have data on their initial income $z_{i}$, the years of schooling of the principal earner, $x_{i}$ and occupational status, $E_{i}$ (with $E_{i}=1$ if the household runs a business and zero otherwise). We estimate the structural parameters (technology and credit access) as well as the distributional parameters of $\theta$ via the generalized method of moments by matching a set of probability of entrepreneurship and income moments in the model 
to their data counterparts for given observed $x_{i}$ and $z_{i}$ (see below for details).

Specifically, the nine parameters we estimate are: $\alpha$ (the elasticity of business revenue with respect to capital), $\lambda$ (the credit constraint parameter), $\gamma$ (the elasticity of non-business income with respect to $x), \eta$ (the parameter governing the occupational choice constraint in $P_{x}$ ), $\mu$ (the scale parameter of non-business income), $\delta_{0}$ (the conditional mean of log talent), $\delta_{1}$ and $\delta_{2}$ (the elasticities of log ability with respect to initial wealth and schooling), and $\sigma$ (the standard deviation of the log-talent distribution). Call the vector of all estimated parameters $\phi \equiv\left(\alpha, \lambda, \gamma, \eta, \mu, \delta_{0}, \delta_{1}, \delta_{2}, \sigma\right)$.

We fix the interest rate parameter $r$ to 1.06, which corresponds to the median level of interest on household loans in the data.

\subsection{GMM - matched moments and computation}

The model parameters are estimated by minimizing the percentage deviation between various moments predicted by the model and their respective sample analogs. Given parameters $\phi$, denote the model-predicted moments by $h_{j}(z, x, \phi)$ for $j=1, \ldots, J$ and their respective sample analogs by $h_{j}^{d}$. Define the percentage deviation of the model predicted moment from its sample analog as

$$
q_{j}(z, x, \phi) \equiv \frac{h_{j}(z, x, \phi)-h_{j}^{d}}{h_{j}^{d}}, \quad j=1, \ldots J
$$

Construct $\mathbf{q}(z, x, \phi)$ as the $J \times 1$ vector of percentage deviations between the model-predicted moments and their sample analogs. The generalized method of moments (GMM) estimates are computed by minimizing the criterion function $\mathbf{q}(z, x, \phi)^{\prime} \mathbf{q}(z, x, \phi)$ over $\phi$. We use an optimization routine robust to local extremes, initialized at the results from an extensive grid search over the parameter space. $^{7}$

For our baseline estimates, we match the 10 moments listed in Table 5 below. The moments are matched by choice of 9 parameters. The first six moments correspond to the probabilities of business ownership in different sub-samples defined based on years of schooling $(x)$ and initial wealth $(z)$. The model-predicted proportion of business owners for a subset of initial wealth levels $z_{i} \in Z$ and years of schooling $x_{i} \in X$ is

$$
\frac{\sum_{i=1}^{N} \mathbf{1}_{\left\{z_{i} \in Z, x_{i} \in X\right\}} P\left(\mathbf{1}_{E}=1 \mid z_{i}, x_{i}, \phi\right)}{\sum_{i=1}^{N} \mathbf{1}_{\left\{z_{i} \in Z, x_{i} \in X\right\}}}
$$

where $P\left(\mathbf{1}_{E}=1 \mid z_{i}, x_{i}, \phi\right)$ is computed using equation (8). The sample analog is the observed fraction of all business owners (those with $E_{i}=1$ ) with $z_{i} \in Z$ and $x_{i} \in X$. The remaining four moments which we match correspond to the average gross incomes of business and non-business households in the full sample or stratified by initial wealth and schooling. For example, the average

\footnotetext{
${ }^{7}$ We first use a grid search over approximately 20,000 parameter configurations. We then initialize the Matlab minimizer particleswarm with an initial population of the 20 best-fitting parameter vectors from the grid search.
} 
expected gross income of a business household in the model is

$$
\frac{\left.\sum_{i=1}^{N} E\left(q^{E} \mid \mathbf{1}_{E}=1, z_{i}, x_{i}, \phi\right)\right)}{\sum_{i=1}^{N} P\left(\mathbf{1}_{E}=1 \mid z_{i}, x_{i}, \phi\right)}
$$

where the expectation in the numerator is taken over $\varepsilon$. The sample analogs are obtained by replacing $P\left(\mathbf{1}_{E}=1 \mid z_{i}, x_{i}, \phi\right)$ with the observed business status, $E_{i}$ and by replacing the conditional gross income expectation $E\left(q \mid \mathbf{1}_{E}=o, z_{i}, x_{i}, \phi\right)$ for $o=\{0,1\}$ by the average observed income of non-business or business households. The expected gross income $E\left(q \mid \mathbf{1}_{E}=1, z_{i}, x_{i}, \phi\right)$ is computed in Appendix B.

Table 5 - List of matched moments

\begin{tabular}{|c|c|c|}
\hline moment & model & sample analog \\
\hline 1. Average probability of entrepreneurship & $\frac{1}{N} \sum_{i=1}^{N} P\left(1_{E}=1 \mid z_{i}, x_{i}, \phi\right)$ & $\frac{1}{N} \sum_{i=1}^{N} E_{i}$ \\
\hline 2. Probability of entrepreneurship, $\mathrm{x} \leq \mathrm{x}_{\mathrm{m}}$ & $\frac{\sum_{i=1}^{N} 1_{\left\{x_{i} \leq x_{m}\right\}} P\left(1_{E}=1 \mid z_{i}, x_{i}, \phi\right)}{\sum_{i=1}^{N} 1_{\left\{x_{i} \leq x_{m}\right\}}}$ & $\frac{\sum_{i=1}^{N} 1_{\left\{x_{i} \leq x_{m}\right\}} E_{i}}{\sum_{i=1}^{N} \mathbf{1}_{\left\{x_{i} \leq x_{m}\right\}}}$ \\
\hline 3. Probability of entrepreneurship, $\mathrm{z} \leq \mathrm{z}_{\mathrm{m}}$ & $\frac{\sum_{i=1}^{N} 1_{\left\{z_{i} \leq z_{m}\right\}} P\left(1_{E}=1 \mid z_{i}, x_{i}, \phi\right)}{\sum_{i=1}^{N} 1_{\left\{z_{i} \leq z_{m}\right\}}}$ & $\frac{\sum_{i=1}^{N} 1_{\left\{z_{i} \leq z_{m}\right\}} E_{i}}{\sum_{i=1}^{N} \mathbf{1}_{\left\{z_{i} \leq z_{m}\right\}}}$ \\
\hline 4. Prob. of entrepreneurship, $\mathrm{z} \leq \mathrm{z}_{\mathrm{m}}, \mathrm{x}>\mathrm{x}_{\mathrm{m}}$ & $\frac{\sum_{i=1}^{N} 1_{\left\{z_{i} \leq z_{m}, x_{i}>x_{m}\right\}} P\left(1_{E}=1 \mid z_{i}, x_{i}, \phi\right)}{\sum_{i=1}^{N} 1_{\left\{z_{i} \leq z_{m}, x_{i}>x_{m}\right\}}}$ & $\frac{\sum_{i=1}^{N} 1_{\left\{z_{i} \leq z_{m}, x_{i}>x_{m}\right\}} E_{i}}{\sum_{i=1}^{N} \mathbf{1}_{\left\{z_{i} \leq z_{m}, x_{i}>x_{m}\right\}}}$ \\
\hline 5. Prob. of entrepreneurship, $\mathrm{z} \leq \mathrm{z}_{\mathrm{m}}, \mathrm{x} \leq \mathrm{x}_{\mathrm{m}}$ & $\frac{\sum_{i=1}^{N} 1_{\left\{z_{i} \leq z_{m}, x_{i} \leq x_{m}\right\}} P\left(1_{E}=1 \mid z_{i}, x_{i}, \phi\right)}{\sum_{i=1}^{N} 1_{\left\{z_{i} \leq z_{m}, x_{i} \leq x_{m}\right\}}}$ & $\frac{\sum_{i=1}^{N} \mathbf{1}_{\left\{z_{i} \leq z_{m}, x_{i} \leq x_{m}\right\}} E_{i}}{\sum_{i=1}^{N} \mathbf{1}_{\left\{z_{i} \leq z_{m}, x_{i} \leq x_{m}\right\}}}$ \\
\hline 6. Prob. of entrepreneurship, $\mathrm{z}>\mathrm{z}_{\mathrm{m}}, \mathrm{x}>\mathrm{x}_{\mathrm{m}}$ & $\frac{\sum_{i=1}^{N} 1_{\left\{z_{i}>z_{m}, x_{i}>x_{m}\right\}} P\left(1_{E}=1 \mid z_{i}, x_{i}, \phi\right)}{\sum_{i=1}^{N} 1_{\left\{z_{i}>z_{m}, x_{i}>x_{m}\right\}}}$ & $\frac{\sum_{i=1}^{N} \mathbf{1}_{\left\{z_{i}>z_{m}, x_{i}>x_{m}\right\}} E_{i}}{\sum_{i=1}^{N} \mathbf{1}_{\left\{z_{i}>z_{m}, x_{i}>x_{m}\right\}}}$ \\
\hline 7. Average gross income, entrepreneurs & $\frac{\left.\sum_{i=1}^{N} E\left(q^{E} \mid 1_{E}=1, z_{i}, x_{i}, \phi\right)\right)}{\sum_{i=1}^{N} P\left(1_{E}=1 \mid z_{i}, x_{i}, \phi\right)}$ & $\frac{\sum_{i=1}^{N} q_{i}^{E} E_{i}}{\sum_{i=1}^{N} E_{i}}$ \\
\hline 8. Average gross income, non-entrepreneurs & $\frac{\left.\sum_{i=1}^{N} E\left(q^{A} \mid 1_{E}=0, z_{i}, x_{i}, \phi\right)\right) P\left(1_{E}=0 \mid z_{i}, x_{i}, \phi\right)}{\sum_{i=1}^{N} P\left(1_{E}=0 \mid z_{i}, x_{i}, \phi\right)}$ & $\frac{\sum_{i=1}^{N} q_{i}^{A}\left(1-E_{i}\right)}{\sum_{i=1}^{N}\left(1-E_{i}\right)}$ \\
\hline 9. Average gross income, entrepreneurs, $\mathrm{z} \leq \mathrm{z}_{\mathrm{m}}$ & $\frac{\left.\sum_{i=1}^{N} 1_{\left\{z_{i} \leq z_{m}\right\}} E\left(q^{E} \mid 1_{E}=1, z_{i}, x_{i}, \phi\right)\right) P\left(1_{E}=1 \mid z_{i}, x_{i}, \phi\right)}{\sum_{i=1}^{N} 1_{\left\{z_{i} \leq z_{m}\right\}} P\left(1_{E}=1 \mid z_{i}, x_{i}, \phi\right)}$ & $\frac{\sum_{i=1}^{N} 1_{\left\{z_{i} \leq z_{m}\right\}} q_{i}^{E} E_{i}}{\sum_{i=1}^{N} 1_{\left\{z_{i} \leq z_{m}\right\}} E_{i}}$ \\
\hline 10. Average gross income, entrepreneurs, $\mathrm{x} \leq \mathrm{x}_{\mathrm{m}}$ & $\frac{\left.\sum_{i=1}^{N} 1_{\left\{x_{i} \leq x_{m}\right\}} E\left(q^{E} \mid 1_{E}=1, z_{i}, x_{i}, \phi\right)\right) P\left(1_{E}=1 \mid z_{i}, x_{i}, \phi\right)}{\sum_{i=1}^{N} 1_{\left\{x_{i} \leq x_{m}\right\}} P\left(1_{E}=1 \mid z_{i}, x_{i}, \phi\right)}$ & $\frac{\sum_{i=1}^{N} 1_{\left\{x_{i} \leq x_{m}\right\}} q_{i}^{E} E_{i}}{\sum_{i=1}^{N} \mathbf{1}_{\left\{x_{i} \leq x_{m}\right\}} E_{i}}$ \\
\hline
\end{tabular}

Notes: $x=$ years of schooling; $z=$ initial wealth; $x_{m}=$ median $x ; z_{m}=$ median $z$. Nine parameters are estimated: $\alpha, \lambda, \gamma, \eta, \mu, \delta_{0}, \delta_{1}, \delta_{2}$ and $\sigma$. 


\subsection{Results}

Table 6 reports the GMM parameter estimates. The return to capital in entrepreneurial income, $\alpha$, is estimated at 0.16 , implying that a 10 percent increase in capital would lead to an approximately $2 \%$ percent increase in entrepreneurial income of unconstrained entrepreneurs, all else equal. The estimate of the credit constraint parameter $\lambda$ is 0.15 , which implies that, for a household with initial wealth equal to the median, the maximum business investment it can afford is about 46,000 Thai baht. As a comparison, the median business assets in the data (for business owning households) is about 19.7 thousand Baht, or close to $6.5 \%$ of the median initial wealth. The choice constraint parameter $\eta$ is estimated to be 0.38 . At the median schooling level $x=4$, this implies a $39 \%$ probability that an agent is constrained in her income-maximizing occupational choice. Entrepreneurial talent $\theta$ is found to be weakly positively related with both initial wealth and years of schooling (the estimates of $\delta_{1}$ and $\delta_{2}$ are positive).

Table 6 - GMM estimates

\begin{tabular}{lc|c}
\hline Parameter & & GMM estimate \\
\hline return to capital in business income & $\alpha$ & 0.164 \\
credit constraint parameter & $\lambda$ & 0.151 \\
return to schooling in non-business income & $\gamma$ & 0.611 \\
tightness of the choice constraint & $\eta$ & 0.382 \\
non-business income parameter & $\mu$ & 40.1 \\
talent - constant & $\delta_{0}$ & 3.24 \\
talent - elasticity w.r.t. initial wealth & $\delta_{1}$ & 0.183 \\
talent - elasticity w.r.t. schooling & $\delta_{2}$ & 0.247 \\
talent - standard deviation & $\sigma$ & 0.979 \\
\hline
\end{tabular}

Table 7 reports the model predictions evaluated at the GMM estimates. We compute these statistics by simulating data from the model at the GMM parameters by drawing 100 random values from the distribution of the shock $\varepsilon$ for each $i=1, \ldots N$. We then average, first over $\varepsilon$ for each $i$, and then over the chosen stratification of agents to compute the different statistics we report in Table 7. The proportion of involuntary entrepreneurs from all households in the sample, as defined in Table 1, is equal to $10.7 \%$. In other words, $16.2 \%$ of the business owners in the sample are classified as involuntary entrepreneurs. The remainder, $55.2 \%$ of all agents or $83.8 \%$ of all business owners are classified as voluntary entrepreneurs at the GMM estimates. Approximately $53 \%$ of all entrepreneurs are credit constrained in the model, that is their capital investment is constrained by $\lambda$ times their initial wealth, $z$. The fraction of constrained entrepreneurs is large among voluntary entrepreneurs $(57.6 \%)$, while much less $(26.1 \%)$ of involuntary entrepreneurs are credit constrained. The reason for these results is that voluntary entrepreneurs have higher entrepreneurial talent on average, and hence larger first-best capital level. Indeed, in the simulated data the average log talent $(\log \theta)$ at the GMM estimates is 5.5 for voluntary entrepreneurs, versus 3.7 for involuntary entrepreneurs and 3.9 for non-entrepreneurs. 
Table 7 - Model predictions at the GMM estimates

\begin{tabular}{l|c}
\hline Model statistic & Value \\
\hline entrepreneurs, \% of all agents & 65.9 \\
involuntary entrepreneurs, \% of all agents & 10.7 \\
involuntary entrepreneurs, \% of all entrepreneurs & 16.2 \\
voluntary entrepreneurs, \% of all agents & 55.2 \\
voluntary entrepreneurs, \% of all entrepreneurs & 83.8 \\
credit constrained, \% of all entrepreneurs & 52.5 \\
credit constrained, \% of voluntary entrepreneurs & 57.6 \\
credit constrained, \% of involuntary entrepreneurs & 26.1 \\
\hline
\end{tabular}

The next table (Table 7b) breaks down the distribution of voluntary and involuntary entrepreneurs in the model by initial wealth, $z$ and years of schooling, $x$ (both taken from the data). The reported percentages in the Table are based on the same simulated data from the model computed at the GMM estimates used in Table 7. We see that the majority (57.4\%) of voluntary entrepreneurs have wealth above the median. This is intuitive, as larger wealth makes it less probable that an entrepreneur will be credit constrained and hence prefer the alternative occupation. This effect is emphasized for schooling above the median, since in that case the alternative income is larger and thus the agents need higher $z$ to be able to invest a sufficient amount to earn higher income as entrepreneurs. The distribution of voluntary entrepreneurs over years of schooling is closer to half and half. The smallest fraction of voluntary entrepreneurs is observed among agents with wealth below the median and schooling above the median. Intuitively, these agents are the most likely to be credit constrained and have a larger potential non-business income.

Looking at involuntary entrepreneurs (panel B of Table $7 \mathrm{~b}$ ), we see that the vast majority (almost 3/4) have years of schooling below the median (6 years) and also close to $2 / 3$ have wealth below the median. There are two reasons for this. First, from our assumptions, the occupational choice constraint which forces households into involuntary entrepreneurship is more restrictive for lower schooling $x$. Second, having lower wealth $z$ makes it more likely that one would be credit constrained if one chose to start a business, and hence prefer the alternative occupation. Indeed, in the simulation $73 \%$ of all credit-constrained involuntary entrepreneurs (19\% of all) have both wealth and schooling below the median while none of the constrained involuntary entrepreneurs have wealth above the median. 
Table $7 \mathrm{~b}$ - Model predictions, distribution of entrepreneurs by type

A. Percent of voluntary entrepreneurs with

\begin{tabular}{l|cc|l} 
& wealth, $z \leq$ median & wealth, $z>$ median & \multicolumn{1}{l}{ total } \\
\hline schooling, $x \leq$ median & 26.5 & 26.5 & 53.0 \\
schooling, $x>$ median & 16.1 & 30.9 & 47.0 \\
total & 42.6 & 57.4 & \\
\hline
\end{tabular}

B. Percent of involuntary entrepreneurs with

\begin{tabular}{l|cc|l} 
& wealth, $z \leq$ median & wealth, $z>$ median & \multicolumn{1}{l}{ total } \\
\hline schooling, $x \leq$ median & 49.1 & 24.6 & 73.7 \\
schooling, $x>$ median & 14.6 & 11.7 & 26.3 \\
total & 63.7 & 36.3 & \\
\hline
\end{tabular}

Figure 1 shows the estimated relationship between initial wealth (in logs) and entrepreneurship and illustrates how our model differs from the purely income maximization model of EJ (1989). The left panel shows the relationship between initial wealth and entrepreneurship overall - it is positive but there is a lot of 'noise'. In contrast, the relationship between initial wealth and voluntary entrepreneurship is strongly positive (the middle panel). This is the picture familiar from EJ (1989) and others, interpreted as indicative of the presence of financial constraints. We see that the relationship between initial wealth and entrepreneurship is made weaker by the presence of a negative relationship between initial wealth and involuntary entrepreneurship (the right-most panel).

Figure 1: Probability of entrepreneurship as function of wealth
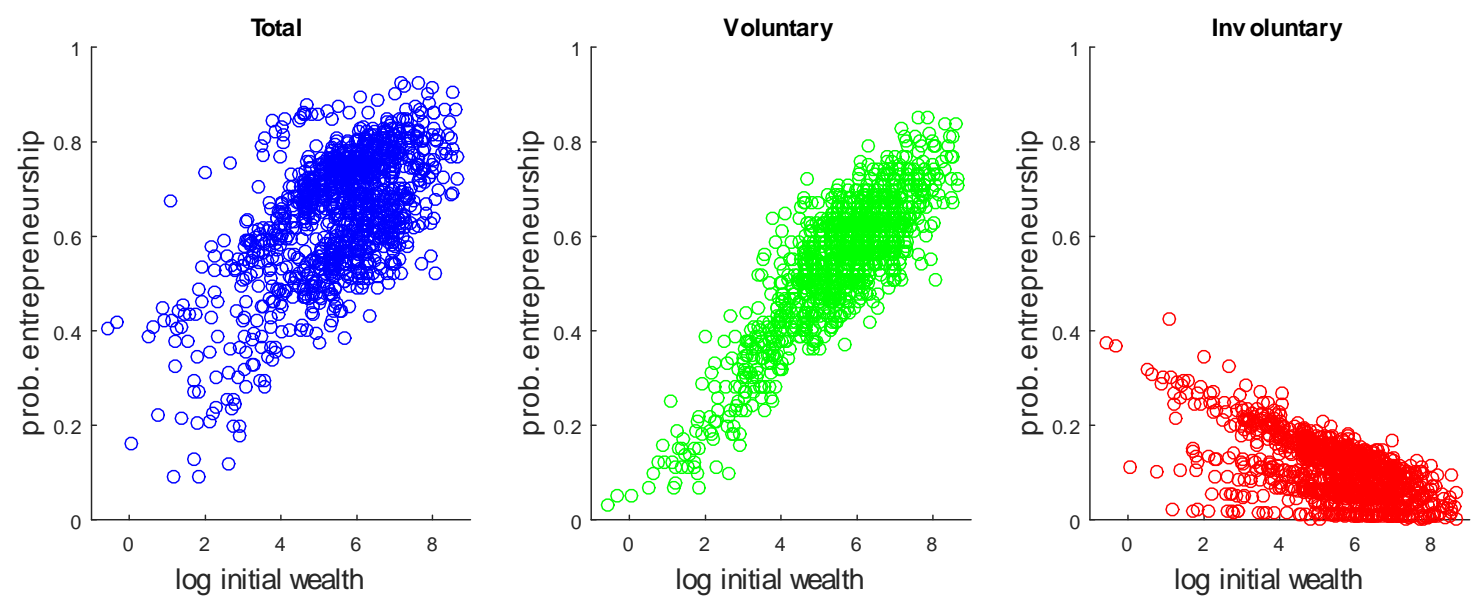

\subsection{Model Fit}

We next assess the model fit to the data, at the GMM parameter estimates. In Table 8 we report the model fit for the 10 chosen moments, as defined in Table 5 above, that we match (target) in 
the GMM estimation routine by minimizing the criterion function over the 9 parameters in $\phi$. We see that all ten matched moments, both the six based on the percentage of entrepreneurs and the four based on average income, are matched within approximately $1.5 \%$ of their counterpart values in the data.

Table 8 - Model Fit: matched moments at GMM estimates

\begin{tabular}{|c|c|c|c|c|}
\hline \multicolumn{2}{|r|}{ moment } & model & data & $\%$ deviation \\
\hline 1. & $\%$ entrepreneurs & 65.9 & 66.1 & 0.29 \\
\hline 2. & $\%$ entrepreneurs, $x$ below median & 74.3 & 74.8 & 0.66 \\
\hline 3. & $\%$ entrepreneurs, $z$ below median & 60.5 & 60.3 & 0.33 \\
\hline 4. & $\%$ entr., $z$ below med., $x$ above median & 48.3 & 49.0 & 1.53 \\
\hline 5. & $\%$ entr., $z$ below med., $x$ below median & 69.9 & 68.9 & 1.33 \\
\hline 6. & $\%$ entr., $z$ above med., $x$ above median & 64.6 & 63.8 & 1.18 \\
\hline 7. & average gross income - entrepreneur & 517.1 & 513.6 & 0.68 \\
\hline 8. & average gross income - non-entrepreneur & 163.5 & 164.7 & 0.67 \\
\hline 9. & avg. gross income - entr., $z$ below median & 352.3 & 350.3 & 0.58 \\
\hline 10. & avg. gross income - entr., $x$ below median & 381.6 & 385.7 & 1.06 \\
\hline \multicolumn{4}{|c|}{ GMM criterion value (sum of squared deviations) } & $8\left(10^{-4}\right)$ \\
\hline
\end{tabular}

Notes: $x_{m}=$ median $x, z_{m}=$ median $z$; income levels in thousands Baht

We next look at additional moments, corresponding to other key dimensions of the model, that we did not target in the GMM estimation (see Table 9). A good fit in these dimensions can be thought of as a 'validation' check of the model with data that have not been used directly in the estimation. $^{8}$ Table 9 indicates that the model fits reasonably well in most of the listed dimensions, with the exception of the percent of entrepreneurs in the 2nd and especially the 4th quartile of years of schooling (lines 5 and 7 in Table 9) where the model overpredicts the number of business owners relative to the data. The model also does not match well the entrepreneurial income for households with both wealth and schooling below the median (deviation of $15 \%$, see line 15 in Table 9), but comes close (within approximately 5\%) in matching the entrepreneurial income for the households with both wealth and schooling above the median (line 16).

\footnotetext{
${ }^{8}$ Moments 1,2,3,12,13 and 14 in Table 9 can be constructed by moments listed in Table 8 and so should fit well by construction if their complements from Table 8 are matched closely.
} 
Table 9 - Model Fit: non-matched moments at GMM estimates

\begin{tabular}{ll|c|c|c}
\hline & \multicolumn{1}{c|}{ moment } & model & data & \% deviation \\
\hline 1. & \% entrepreneurs, $x$ above median & 57.5 & 57.4 & 0.18 \\
2. & \% entrepreneurs, $z$ above median & 71.3 & 71.9 & 0.82 \\
3. & \% entr., $z$ above median, $x$ below median & 80.2 & 82.5 & 2.84 \\
4. & \% entrepreneurs, $x$ in 1st quartile & 76.4 & 79.5 & 3.96 \\
5. & \% entrepreneurs, $x$ in 2nd quartile & 67.3 & 58.8 & 14.4 \\
6. & \% entrepreneurs, $x$ in 3rd quartile & 59.5 & 66.5 & 10.5 \\
7. & \% entrepreneurs, $x$ in 4th quartile & 53.1 & 37.3 & 42.4 \\
8. & \% entrepreneurs, $z$ in 1st quartile & 55.7 & 60.3 & 7.63 \\
9. & \% entrepreneurs, $z$ in 2nd quartile & 65.4 & 60.4 & 8.24 \\
10. & \% entrepreneurs, $z$ in 3rd quartile & 69.6 & 72.0 & 3.39 \\
11. & \% entrepreneurs, $z$ in 4th quartile & 73.0 & 71.7 & 1.77 \\
12. & average gross income - all & 396.6 & 395.3 & 0.32 \\
13. & avg. gross income - entr., $z$ above median & 657.3 & 651.0 & 0.98 \\
14. & avg. gross income - entr., $x$ above median & 692.5 & 680.6 & 1.76 \\
15. & avg. gross income - entr., $z$ and $x$ below med. & 283.5 & 335.5 & 15.4 \\
16. & avg. gross income - entr., $z$ and $x$ above med. & 812.0 & 858.0 & 5.36 \\
\hline
\end{tabular}

Note: income levels are in thousands Baht

Figure 2 further clarifies the patterns we see in Table 9 with regards to where the model succeeds or fails to match the predicted probability/fraction of entrepreneurship relative to what is observed in the data. The Figure plots lowess regression lines and confidence intervals around the data. We see that, at the GMM parameters the model matches well the overall level and slope of the lowess lines from the data (both with respect to initial wealth and schooling). However, the model struggles to match the data at very low levels of wealth (it under-predicts entrepreneurship) and at very low or high levels of schooling (it over-predicts entrepreneurship). 
Figure 2: Probability of Entrepreneurship - Model vs. Data
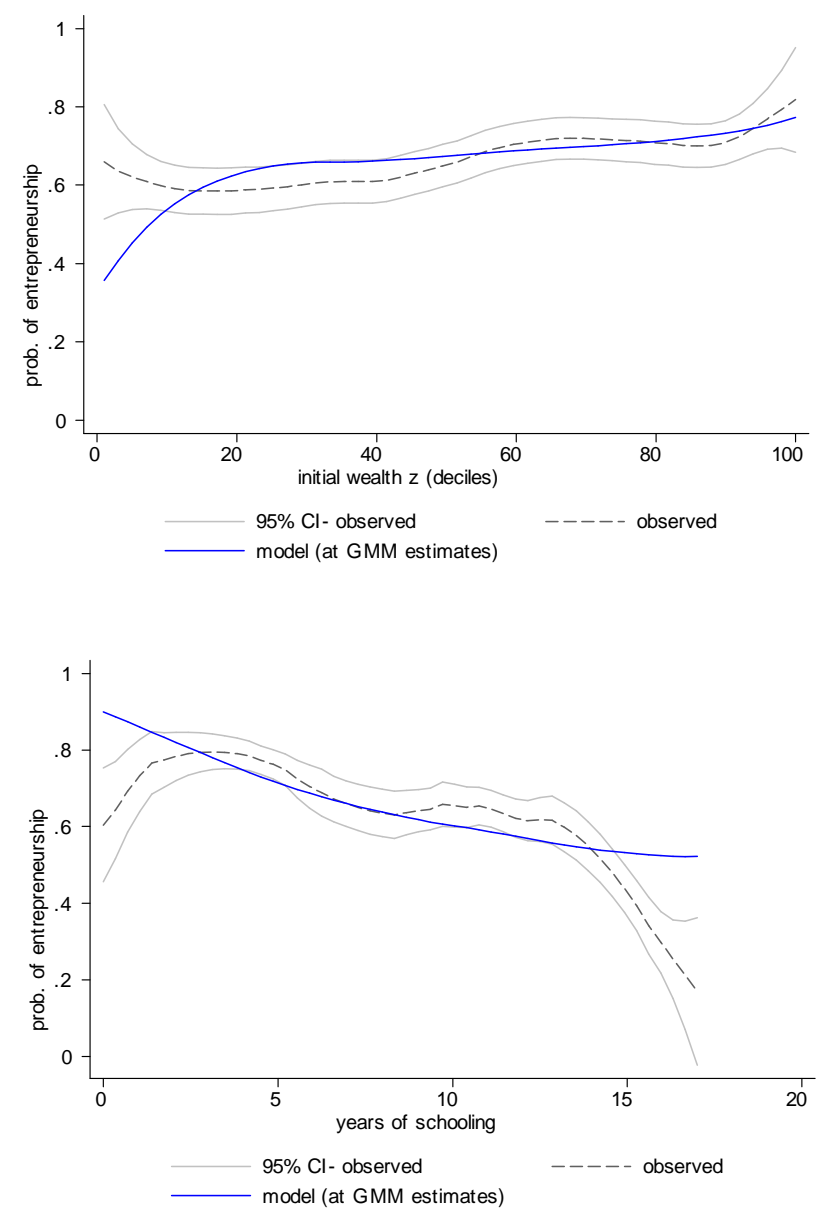

\section{$5 \quad$ Policy counterfactuals}

\subsection{Relaxing the labor or credit constraints}

In the model, involuntary entrepreneurship arises if both of the following conditions are true: (i) the household does not have access to the alternative occupation (for example, a wage job), which we can interpret as a labor market constraint or friction and (ii) household income is maximized in the alternative occupation. The labor constraint is important for condition (i), while the credit constraint affects (ii). We compute the model at the GMM estimates to evaluate and isolate the effects of the two constraints on entrepreneurship - overall and its decomposition into voluntary and involuntary. We also report the effects of the two constraints on household income.

In the first counterfactual, we set the parameter $\eta$ to zero while keeping all other parameters at their GMM estimates. This means that involuntary entrepreneurship is completely eliminated - all households have free occupational choice, for example, as in EJ (1989). This also affects average income in the economy since previously involuntary entrepreneurs are now able to choose the non-business occupation as income maximizing. Voluntary entrepreneurs are not affected by the 
elimination of the labor constraint as no new such entrepreneurs appear. The results are reported in Table 10 and are computed from the model-simulated data at the GMM estimates. ${ }^{9}$ In panel A we see that the elimination of the labor constraint reduces the rate of entrepreneurship to $55.3 \%$. In panel B we compute the expected net income (mean, median, and percentiles) for each household defined as $E\left(q^{E}-r k+(r-1) z\right)$ for entrepreneurs, which equals output revenue minus the cost of capital plus interest income, and the expectation is taken over the talent shock $\varepsilon$. Similarly we compute net income as $q^{A}+(r-1) z$ for non-entrepreneurs. Net income, as opposed to gross, is what households use in their occupational choice. We then average the net incomes across households. Table 10 shows that average net income is the highest for voluntary entrepreneurs and the lowest for involuntary entrepreneurs. This is intuitive, since by assumption, involuntary entrepreneurs would be more productive in the non-business occupation.

We see that eliminating the labor constraint increases income throughout the income distribution (see the second column in Panel B). The change from the baseline income indicates the change in the income distribution at the mean, median and different percentiles. As such it includes the effects of any mobility within the income distribution as a result of the counterfactual. For example, an ex-ante involuntary entrepreneur who is now free to work in the alternative occupation could move from the 10th to the 30 th percentile, etc. We see that relaxing the labor constraint has a strongest effect at the 10th income percentile, which are most likely to be involuntary entrepreneurs ex-ante. We also see a large positive effect on the mean entrepreneurial income (16\% increase) which is accompanied with a fall in average income of non-business agents (-5.3\%). This should not be confused with a negative impact on income - it is clear that no one can lose from the relaxation of the labor constraint - everyone's income weakly increases as they can either stay in their current occupation or switch to their preferred one. ${ }^{10}$ Instead, the reason is a pure composition effect - some unproductive entrepreneurs (with low talent $\theta$ and low schooling $x$ ) exit the business occupation and enter the alternative occupation. Finally, relaxing the labor constraint also affects the number of constrained entrepreneurs (those with $k=\lambda z$ ). The simulated data show that the percent of constrained entrepreneurs increases from $52.5 \%$ in the baseline to $57.6 \%$ (not reported in the table). The reason is that all remaining entrepreneurs are now voluntary and have higher talent $\theta$.

\footnotetext{
${ }^{9}$ In contrast, the statistics reported in Table 9 use the analytical expressions for mean income.

${ }^{10}$ Of course, this is only true abstracting from general equilibrium effects that we do not model.
} 
Table 10 - Relaxing the labor or credit constraints

\begin{tabular}{|c|c|c|c|}
\hline & baseline & free occ. choice $(\eta=0)$ & relaxed credit $(2 \lambda)$ \\
\hline \multicolumn{4}{|l|}{ A. Occupational choice } \\
\hline entrepreneurs & $65.9 \%$ & $55.3 \%$ & $66.4 \%$ \\
\hline of which voluntary & $83.9 \%$ & $100 \%$ & $84.2 \%$ \\
\hline of which involuntary & $16.1 \%$ & $0 \%$ & $15.8 \%$ \\
\hline B. Net income & baseline & change from baseline & change from baseline \\
\hline mean, all & 396.4 & $+1.7 \%$ & $+3.4 \%$ \\
\hline 10th percentile & 190.3 & $+6.8 \%$ & $+6.9 \%$ \\
\hline 30th percentile & 285.8 & $+2.8 \%$ & $+4.9 \%$ \\
\hline median & 362.5 & $+2.2 \%$ & $+4.2 \%$ \\
\hline 70th percentile & 455.3 & $+1.4 \%$ & $+3.4 \%$ \\
\hline 90th percentile & 638.6 & $+0.8 \%$ & $+3.4 \%$ \\
\hline mean, entrepreneurs & 502.3 & $+16 \%$ & $+3.5 \%$ \\
\hline mean, voluntary entr. & 582.6 & no change & $+3.4 \%$ \\
\hline mean, involuntary entr. & 84.8 & n.a. & $+0.4 \%$ \\
\hline mean, non-business & 191.3 & $-5.3 \%$ & $+0.2 \%$ \\
\hline
\end{tabular}

The second counterfactual we study is relaxing the credit constraint which we achieve by doubling the estimate of $\lambda$ from the baseline (from 0.15 to 0.3 ), keeping all other parameters at their GMM estimates. We see in the model-simulated data that relaxing the credit constraint has a minor effects on involuntary entrepreneurship (its share falls from $16.1 \%$ to $15.8 \%$ ) and on entrepreneurship overall (it increases from $65.9 \%$ to $66.4 \%$ ). This can be interpreted as suggestive that the labor market constraint rather than the credit constraint is more important in causing involuntary entrepreneurship. We do see, however, that relaxing the credit constraint has a significant impact on households' income. The average increase in net income is double that of relaxing the labor constraint, with the impact more evenly spread across the income distribution. Still, as in the first counterfactual, the 10th percentile experiences the largest income change $(+6.9 \%)$ as those agents become able to invest closer to their desired capital level. The voluntary entrepreneurs gain about the same as the average agent, while the involuntary entrepreneurs and non-entrepreneurs obtain only minor income gains, the former since they are mostly constrained by talent, the latter due to the minor composition shift in the economy towards entrepreneurship.

Looking at the number of constrained households in the simulated data (not reported in the table), unsurprisingly we see a large drop from $52.5 \%$ to $34 \%$ in the fraction of constrained entrepreneurs. Among voluntary entrepreneurs, the fraction of constrained falls from $57.6 \%$ to $37.4 \%$ while the corresponding impact among involuntary entrepreneurs is a decrease in the fraction of constrained from $26.1 \%$ to $15.7 \%$.

We also illustrate the distribution of income gains from each of the two counterfactuals on Figure 3, stratified by $\log$ initial wealth, $z$ and years of schooling, $x$. Note that in our setting income gains can be interpreted as welfare gains. We use the simulated data from the model to 
compute the change in expected income (integrated over the talent shock $\varepsilon$ ) of each households with characteristics $\left(z_{i}, x_{i}\right)$ from the data, before vs. after the policy. The Figure shows that relaxing the labor constraint (setting $\eta=0$ ) leads to much larger income gains for some individuals (up to $40 \%$ ). These gains are monotonically decreasing on average in initial wealth and years of schooling (as it is less likely that a household used to be an involuntary entrepreneur for high $z$ and $x$ ). In contrast, the income gains from relaxing the credit constraint (doubling the estimated value of $\lambda$ ) are non-monotonic over initial wealth, with households with intermediate wealth levels gaining the most. The reason is that they are most likely to be constrained entrepreneurs.

Figure 3: Expected Income Gains - Relaxing the Labor or Credit Constraints
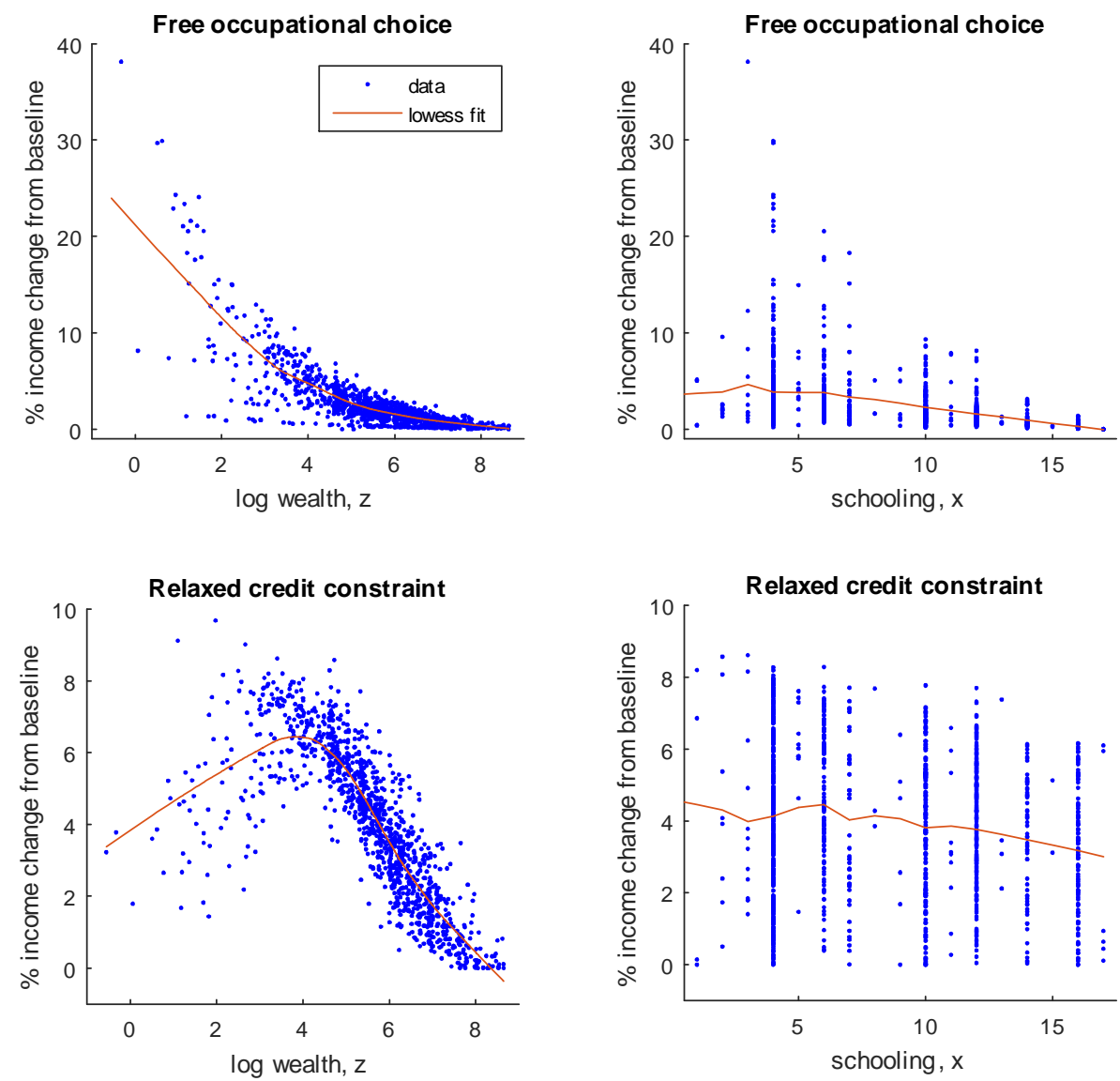

\subsection{Microfinance}

We next consider the counterfactual of offering households the option to borrow and invest up to an additional $M$ dollars. For example, this could be thought of in the context of a microfinance program. The requirement is that the loan can be only used to buy/rent business capital, at the current interest rate $r$. We analyze the effect of this policy counterfactual on the rate of involuntary 
entrepreneurship and household income. All model parameters are held at the baseline GMM estimates. We set the maximum loan size to $10 \%$ of the median gross income in our sample, $M=20,000$ Baht.

Households optimally choose $k$ to solve

$$
\max _{k} \theta k^{\alpha}-r k \quad \text { subject to } \quad k \leq \lambda z+M
$$

and optimally choose to run a business if their income from entrepreneurship, using the re-optimized $k$, is higher than the alternative (unaffected by the policy). Clearly, all previously unconstrained households are unaffected by this policy while all constrained ones would have an incentive to participate.

Table 11 shows the effects of the policy on occupational choice and income, by various groups of households. We see that the fraction of entrepreneurs goes up by almost 1 percentage point. In addition, within that increased number of businesses the policy induces more voluntary entrepreneurship and the rate of involuntary entrepreneurs falls to $15.5 \%$. In terms of the effect on the distribution of income, the microfinance loan raises average income by $3 \%$ but the gains are not evenly spread among the different households. The poorest 10-th percentile benefits the most (a raise in income by $12.2 \%$ post vs. pre-policy) from the availability of additional credit while the top 10-th percentile benefits only marginally - these are households that are more likely to be unconstrained ex-ante.

The mean income of entrepreneurs goes up for two reasons - first, the additional credit relaxes the financial constraint and allows entrepreneurs to earn more and second, there is a compositional shift from involuntary to voluntary entrepreneurs. The mean non-business income also goes up as some agents with low schooling exit the occupation. 
Table 11 - Policy Counterfactual

\begin{tabular}{l|c|c}
\hline \multicolumn{2}{c}{ baseline } & microfinance loan \\
\hline A. Occupational choice \\
\hline entrepreneurs & $65.9 \%$ & $66.8 \%$ \\
of which voluntary & $83.9 \%$ & $84.5 \%$ \\
of which involuntary & $16.1 \%$ & $15.5 \%$ \\
\hline B. Net income & baseline & change from baseline \\
\hline mean, all & 396.4 & $+3.0 \%$ \\
10th percentile & 190.3 & $+12.2 \%$ \\
30th percentile & 285.8 & $+5.1 \%$ \\
median & 362.5 & $+2.9 \%$ \\
70th percentile & 455.3 & $+1.9 \%$ \\
90th percentile & 638.6 & $+1.0 \%$ \\
mean, entrepreneurs & 502.3 & $+2.7 \%$ \\
mean, voluntary entr. & 582.6 & $+2.1 \%$ \\
mean, involuntary entr. & 84.8 & $+0.9 \%$ \\
mean, non-business & 191.3 & $+0.4 \%$ \\
\hline
\end{tabular}

The effects of the microfinance loan policy on income are illustrated on Figure 4, stratified by $\log$ initial wealth, $z$ and years of schooling, $x$. We use the simulated data from the model and compute the change in expected income (integrated over the talent shock $\varepsilon$ ) of each households with characteristics $\left(z_{i}, x_{i}\right)$ from the data before and after the policy. We see that the policy benefits poorer households significantly (income gains of 30-40 percent relative to the baseline). The gains quickly dissipate for wealthier households as they are less likely to have been constrained and hence benefit from the access to microfinance. In contrast, the income gains are more spread out by years of schooling. This is due to the interaction of wealth and schooling in the data. The bottom panel of the figure shows that the households who gain the most from the policy are those with the lowest wealth and schooling. Low-wealth agents with high schooling do not gain much, as they are likely to be engaged in the alternative occupation for most values of $\varepsilon$. Only the involuntary entrepreneurs among them stand to gain from the microfinance policy.

\subsection{Other counterfactuals [to do]}

1. Transfer to households below certain wealth or income.

2. Increase in skills $x$ (e.g., an education policy raising years of schooling).

\section{Robustness Checks [to do]}

1. alternative definition of "in business" based on major source of income

2. alternative specification of the labor market (occupational choice) constraint 
Figure 4: Microfinance - income gains by wealth and schooling
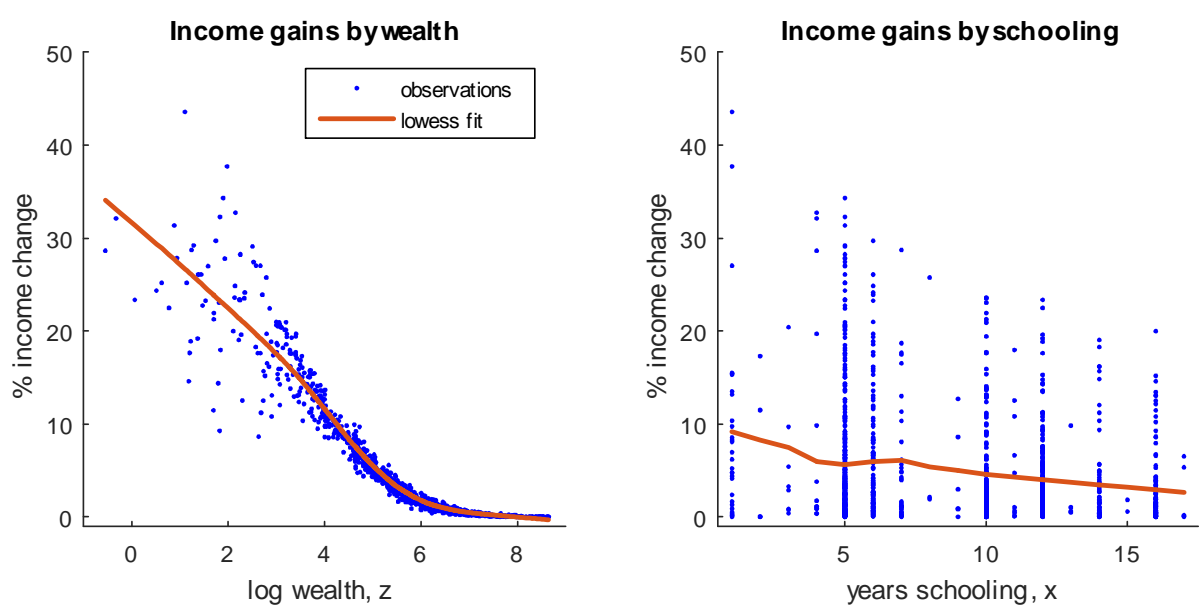

Income gains by wealth and schooling (smoothed)

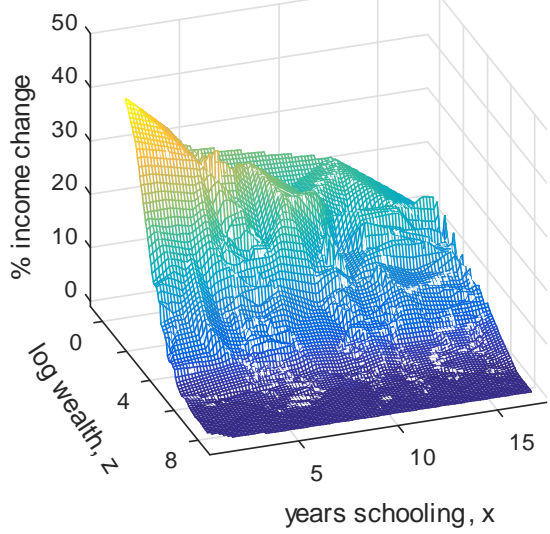

3. estimate via MLE with occupational choice only as in PTK (2006) or Karaivanov (2012) [fits badly on income]

\section{Conclusions}

The classical theory of occupational choice is predicated on the observed choice being better than the next best alternative. In this paper, we empirically explore the idea that some of the observed occupational choices are involuntary, especially in the context of developing countries. We model and estimate structurally the possibility that agents do not have access to wage employment, allowing the standard model of free occupational choice as a nested case. We define involuntary entrepreneurs as those entrepreneurs who maximize their income in a non-entrepreneurial job, but who are not able to access that job due to frictions in the labor market. Our results classify about $16 \%$ of all 
business owners as involuntary entrepreneurs.

\section{References}

[1] Aghion, P. and P. Bolton. 1997. A theory of trickle-down growth and development. Review of Economic Studies 64(2): 151-172.

[2] Banerjee, A. and E. Duflo. 2007. The economic lives of the poor. Journal of Economic Perspectives 21(1): 141-168.

[3] Banerjee, A., E. Breza, E. Duflo and C. Kinnan. 2015. Do credit constraint limit entrepreneurship? Heterogeneity in the returns to microfinance. working paper.

[4] Banerjee, A. and E. Duflo. 2011. Poor economics: a radical rethinking of the way to fight global poverty. New York: Public Affairs.

[5] Banerjee, A. and A. Newman. 1993. Occupational choice and the process of development. Journal of Political Economy 101(2): 274-298.

[6] Block, J. and M. Wagner. 2010. Necessity and opportunity entrepreneurs in Germany: characteristics and earnings differentials. Schmalenbach Business Review 62: 154-174.

[7] de Mel, S., D. McKenzie and C. Woodruff. 2010. Who are the microenterprise owners? Evidence from Sri Lanka on Tokman v. de Soto. International Differences in Entrepreneurship. Joshua Lerner and Antoinette Schoar (Eds.): 63-87.

[8] Donovan, K. 2014. Subsistence entrepreneurs and misallocation. Working paper.

[9] Earle, J. and Z. Sakova. 2007. Business start-ups or disguised unemployment? Evidence on the character of self-employment from transition economies. Labor Economics 7: 575-601.

[10] Falco, P. and L. Haywood. 2013. Entrepreneurship versus joblessness: explaining the rise in self-Employment. Discussion Papers of DIW Berlin 1334, DIW Berlin, German Institute for Economic Research.

[11] Fields, Gary S. 2005. A guide to multisector labor market models. Social Protection Discussion Papers 3254\%. The World Bank.

[12] Gunther, I. and A. Launov. 2012. Informal employment in developing countries. Journal of Development Economics 97(1): 88-98.

[13] Karaivanov, A. 2012. Financial constraints and occupational choice in Thai villages. Journal of Development Economics 97(2): 201-220.

[14] Lloyd-Ellis, H. and D. Bernhardt. 2000. Enterprise, inequality and economic development. The Review of Economic Studies 67(1): 147-168. 
[15] Mazumdar, D. 1983. Segmented labor markets in LDCs. The American Economic Review 73(2): 254-259.

[16] Nguimkeu, P. 2014. A structural econometric analysis of the informal sector heterogeneity. Journal of Development Economics 107(C): 175-191.

[17] NORC at the University of Chicago, Thai Fiscal Policy Office. 2008. Townsend Thai Project Initial Household Survey 2005 (Urban Area) [Computer file]. 1st Data Distributor Version: NORC at The University of Chicago, Fiscal Policy Office [Producer]. Bangkok, Thailand: The University of Chicago-UTCC Research Center [distributor].

[18] Paulson, A., R. Townsend and A. Karaivanov. 2006. Distinguishing limited liability from moral hazard in a model of entrepreneurship. Journal of Political Economy 144(1): 100-144.

[19] Piketty, T. 1997. The dynamics of the wealth distribution and the interest rate with credit rationing. Review of Economic Studies 64(2): 173-189.

[20] Poshke, M. 2012. Entrepreneurs out of necessity: a snapshot. mimeo, McGill University.

[21] Reynolds, P., N. Bosma, E. Autio, S. Hunt, N. De Bono, I. Servais, P. Lopez-Garcia and N. Chin. 2005. Global Entrepreneurship Monitor: Data Collection Design and Implementation 1998-2003. Small Business Economics 24: 205-231.

\section{Appendices}

\subsection{Appendix A - Proofs}

\section{Proof of Proposition 1}

Using the definitions of $y^{E}(\theta, z), y^{A}(z, x)$ and $\Delta(z, \theta, x)$, we obtain,

$$
\Delta(z, \theta, x) \geq 0 \Leftrightarrow\left\{\begin{array}{cc}
(1-\alpha) \theta^{\frac{1}{1-\alpha}}\left(\frac{\alpha}{r}\right)^{\frac{\alpha}{1-\alpha}}-\mu(1+x)^{\gamma} \geq 0 & \text { if } \theta \leq B(z) \\
\theta(\lambda z)^{\alpha}-r \lambda z-\mu(1+x)^{\gamma} \geq 0 & \text { if } \theta>B(z)
\end{array}\right.
$$

which, in terms of the agent's entrepreneurial ability $\theta$, is equivalent to,

$$
\Delta(z, \theta, x) \geq 0 \Leftrightarrow\left\{\begin{array}{cc}
\theta \geq\left(\frac{\mu}{1-\alpha}\right)^{1-\alpha}(1+x)^{\gamma(1-\alpha)}\left(\frac{r}{\alpha}\right)^{\alpha} & \text { if } \theta \leq B(z) \\
\theta \geq(\lambda z)^{-\alpha}\left[\mu(1+x)^{\gamma}+r \lambda z\right] & \text { if } \theta>B(z)
\end{array}\right.
$$

\section{Proof of Lemma 1:}

Using (5), we have, since $\mathbf{1}_{B>A}=\mathbf{1}_{B>C}$,

$$
\begin{aligned}
& \tilde{P}_{E}=P(\Delta \geq 0)=\mathbf{1}_{B>}\left\{P\left(\frac{\varepsilon}{\sigma}>\frac{\ln B-\bar{\theta}}{\sigma}\right)+P\left(\frac{\ln A-\bar{\theta}}{\sigma} \leq \frac{\varepsilon}{\sigma} \leq \frac{\ln B-\bar{\theta}}{\sigma}\right)\right\}+ \\
&+\left(1-\mathbf{1}_{B>A}\right) P\left(\frac{\varepsilon}{\sigma} \geq \frac{\ln C-\bar{\theta}}{\sigma}\right)
\end{aligned}
$$


Let $\Phi(\cdot)$ be the standard normal cumulative density function. We then obtain,

$$
\begin{aligned}
& P(\Delta \geq 0)=\mathbf{1}_{B>A}\left\{1-\Phi\left(\frac{\ln B-\bar{\theta}}{\sigma}\right)+\Phi\left(\frac{\ln B-\bar{\theta}}{\sigma}\right)-\Phi\left(\frac{\ln A-\bar{\theta}}{\sigma}\right)\right\}+ \\
&+\left(1-\mathbf{1}_{B>A}\right)\left\{1-\Phi\left(\frac{\ln C-\bar{\theta}}{\sigma}\right)\right\}= \\
&=\mathbf{1}_{B>A}\left\{1-\Phi\left(\frac{\ln A-\bar{\theta}}{\sigma}\right)\right\}+\left(1-\mathbf{1}_{B>A}\right)\left\{1-\Phi\left(\frac{\ln C-\bar{\theta}}{\sigma}\right)\right\}
\end{aligned}
$$

which is equivalent to the Lemma statement.

\subsection{Appendix B - Derivation of the income moments}

We derive the expected gross income conditional on business ownership. Recall that the expected entrepreneurial output is defined as $q^{E}(\theta, z)=\theta k^{\alpha}$. The expected output, conditional on being an entrepreneur (and conditional on observables $z$ and $x$, but we suppress these dependencies for notational ease) is,

$$
\begin{aligned}
E\left(q^{E} \mid 1_{E}\right. & =1)=\int q^{E}(\theta) f\left(\theta \mid 1_{E}=1\right) d \theta=\int q^{E}(\theta) \frac{f\left(\theta, 1_{E}=1\right)}{P\left(1_{E}=1\right)} d \theta= \\
& =\int q^{E}(\theta) \frac{f(\theta, \Delta \geq 0)+P_{x} f(\theta, \Delta<0)}{P\left(1_{E}=1\right)} d \theta= \\
& =\frac{P(\Delta \geq 0)}{P\left(1_{E}=1\right)} \int q^{E}(\theta) \frac{f(\theta, \Delta \geq 0)}{P(\Delta \geq 0)} d \theta+\frac{P_{x} P(\Delta<0)}{P\left(1_{E}=1\right)} \int q^{E}(\theta) \frac{f(\theta, \Delta<0)}{P(\Delta<0)} d \theta= \\
& =\frac{P(\Delta \geq 0)}{P\left(1_{E}=1\right)} \int q^{E}(\theta) f(\theta \mid \Delta \geq 0) d \theta+\frac{P_{x} P(\Delta<0)}{P\left(1_{E}=1\right)} \int q^{E}(\theta) f(\theta \mid \Delta<0) d \theta= \\
& =\frac{P(\Delta \geq 0)}{P\left(1_{E}=1\right)} E\left(q^{E} \mid \Delta \geq 0\right)+\frac{P_{x} P(\Delta<0)}{P\left(1_{E}=1\right)} E\left(q^{E} \mid \Delta<0\right)
\end{aligned}
$$

The probabilities $P(\triangle<0)$ and $P(\triangle \geq 0)$ were computed in Lemma 1 . We also have

$$
\begin{aligned}
E\left(q^{E} \mid \triangle\right. & <0)=E\left(q^{E} \mid \triangle<0, \theta>B\right) P(\theta>B \mid \triangle<0)+E\left(\ln q^{E} \mid \triangle<0, \theta \leq B\right) P(\theta \leq B \mid \triangle<0) \\
& =E\left(q^{E} \mid \triangle<0, \theta>B\right) \frac{P(\theta>B, \triangle<0)}{P(\Delta<0)}+E\left(q^{E} \mid \triangle<0, \theta \leq B\right) \frac{P(\theta \leq B, \triangle<0)}{P(\Delta<0)} \\
& =E\left(q^{E} \mid \triangle<0, \theta>B\right) \frac{P(\theta>B, \theta<C)}{P(\Delta<0)}+E\left(q^{E} \mid \triangle<0, \theta \leq B\right) \frac{P(\theta \leq B, \theta<A)}{P(\Delta<0)} \\
& =E\left(q^{E} \mid \triangle<0, \theta>B\right) \frac{\left(1-1_{B>A}\right)(\Phi(c)-\Phi(b))}{P(\Delta<0)}+E\left(q^{E} \mid \triangle<0, \theta \leq B\right) \frac{\Phi(\min (a, b))}{P(\Delta<0)}
\end{aligned}
$$

and 


$$
\begin{aligned}
E\left(q^{E} \mid \triangle\right. & \geq 0)=E\left(q^{E} \mid \triangle \geq 0, \theta>B\right) P(\theta>B \mid \triangle \geq 0)+E\left(q^{E} \mid \triangle \geq 0, \theta \leq B\right) P(\theta \leq B \mid \triangle \geq 0) \\
& =E\left(q^{E} \mid \triangle \geq 0, \theta>B\right) \frac{P(\theta>B, \triangle \geq 0)}{P(\Delta \geq 0)}+E\left(q^{E} \mid \triangle \geq 0, \theta \leq B\right) \frac{P(\theta \leq B, \triangle \geq 0)}{P(\Delta \geq 0)} \\
& =E\left(q^{E} \mid \triangle \geq 0, \theta>B\right) \frac{P(\theta>B, \theta \geq C)}{P(\Delta \geq 0)}+E\left(q^{E} \mid \triangle \geq 0, \theta \leq B\right) \frac{P(\theta \leq B, \theta \geq A)}{P(\Delta \geq 0)} \\
& =E\left(q^{E} \mid \triangle \geq 0, \theta>B\right) \frac{1-\Phi(\max (b, c))}{P(\Delta \geq 0)}+E\left(q^{E} \mid \triangle \geq 0, \theta \leq B\right) \frac{1_{B>A}(\Phi(b)-\Phi(a))}{P(\Delta \geq 0)}
\end{aligned}
$$

and where:

1. $\left.E\left(q^{E} \mid \triangle<0, \theta>B\right)=E\left\{(\lambda z)^{\alpha} \theta \mid B<\theta<C\right)\right\}=(\lambda z)^{\alpha} E(\theta \mid B<\theta<C)$

2. $E\left(q^{E} \mid \triangle<0, \theta \leq B\right)=E\left\{\left(\frac{\alpha}{r}\right)^{\frac{\alpha}{1-\alpha}} \theta^{\frac{1}{1-\alpha}} \mid \theta \leq \min (A, B)\right\}$

$$
=\left(\frac{\alpha}{r}\right)^{\frac{\alpha}{1-\alpha}} E\left(\theta^{\frac{1}{1-\alpha}}\right) \frac{\Phi(\min (a, b)-\{\sigma /(1-\alpha)\})}{\Phi(\min (a, b))} \text {, where } E\left(\theta^{\frac{1}{1-\alpha}}\right)=\exp \left(\frac{\bar{\theta}}{1-\alpha}+\frac{\sigma^{2}}{2(1-\alpha)^{2}}\right) \text {. }
$$

3. $E\left(q^{E} \mid \triangle \geq 0, \theta>B\right)=E\left\{(\lambda z)^{\alpha} \theta \mid \theta \geq \max (B, C)\right\}$

$$
=(\lambda z)^{\alpha} E(\theta) \frac{\Phi(\sigma-\max (b, c))}{\Phi(-\max (b, c))} .
$$

4. $E\left(q^{E} \mid \triangle \geq 0, \theta \leq B\right)=E\left\{\left(\frac{\alpha}{r}\right)^{\frac{\alpha}{1-\alpha}} \theta^{\frac{1}{1-\alpha}} \mid A \leq \theta \leq B\right\}$

$$
=\left(\frac{\alpha}{r}\right)^{\frac{\alpha}{1-\alpha}} E\left(\theta^{\frac{1}{1-\alpha}}\right) \frac{\Phi(\{\sigma /(1-\alpha)\}-a)-\Phi(\{\sigma /(1-\alpha)\}-b)}{\Phi(b)-\Phi(a)} .
$$

